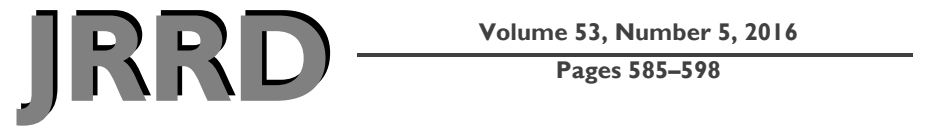

\section{Everyday sitting behavior of full-time wheelchair users}

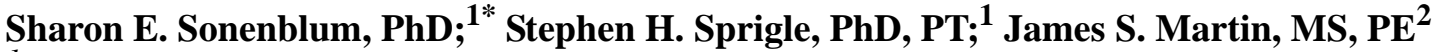 \\ ${ }^{1}$ Rehabilitation Engineering and Applied Research Laboratory, Georgia Institute of Technology, Atlanta, GA; ${ }^{2}$ George \\ W. Woodruff School of Mechanical Engineering, Georgia Institute of Technology, Atlanta, GA
}

\begin{abstract}
The objective of this study was to describe the inseat movement and weight-shifting behavior of full-time wheelchair users. We measured everyday sitting behavior for $192 \mathrm{~d}$ across 28 individuals who used manual wheelchairs as their primary mobility device. To obtain the measurements, we used eight thin force sensors placed under participants' wheelchair cushions. On a typical day, participants spent an average of $10.6+/-3.0 \mathrm{~h}$ in their wheelchair and transferred out of the wheelchair $8.4+/-4.3$ times. Participants only performed pressure reliefs (90\% off-loading of the entire buttocks for at least 15 s) $0.4+/-0.5$ times per hour they were seated in the chair, but they performed weight shifts (WSs) (30\%-90\% off-loading of at least one side of the buttocks for $15 \mathrm{~s}$ ) with a frequency of $2.4+/-2.2$ times per hour. Despite the higher frequency of WSs, they were not performed in a routine manner. Half of the days studied included one segment of upright sitting lasting at least $2 \mathrm{~h}$ without a WS. Given these observations, we conclude that seating evaluations should emphasize positioning individuals in a way that facilitates reaching, leaning, and transferring in a safe manner, not only to improve function but also to affect buttocks loading.
\end{abstract}

Key words: activity, behavior, buttocks, interface pressure, monitoring, pressure relief, pressure ulcer, sitting, spinal cord injury, weight shift, wheelchair.

\section{INTRODUCTION}

For many wheelchair users, the combination of reduced mobility and impaired sensation results in a lifetime risk of developing pressure ulcers. In addition to the medical costs, the development of a pressure ulcer adversely affects activities of daily living, employment, and overall quality of life.

The formation and underlying causes of pressure ulcers are quite complex, with multiple influencing factors. However, tissue loading is the defining cause of pressure ulcers and distinguishes them from other insults such as vascular and ischemic ulcers [1-2]. The mechanisms by which tissue loading leads to tissue breakdown have not been established [3], but current theories suggest that a combination of cell damage from prolonged deformation, ischemia of soft tissues, and a disruption in the equilibrium of the lymphatic system are involved [46]. Long-standing research has clearly demonstrated that the damaging effects of pressure are related to both its magnitude and duration [1-2], which is consistent with the proposed mechanisms of damage. Simply stated, tissues can withstand higher loads for shorter periods of time.

Clinical interventions have been based on the premise that both the magnitude and duration of loading are

Abbreviations: $\mathrm{COP}=$ center of pressure, $\mathrm{PPI}=$ peak pressure index, $\mathrm{PR}=$ pressure relief, $\mathrm{PRM}=$ pressure relief monitoring, SCI = spinal cord injury, WS = weight shift.

*Address all correspondence to Sharon E. Sonenblum, PhD; Rehabilitation Engineering and Applied Research Laboratory, Georgia Institute of Technology, 490 10th Street NW, Atlanta, GA 30318; 404-385-0633.

Email: ss427@gatech.edu

http://dx.doi.org/10.1682/JRRD.2015.07.0130 
important. The effect of magnitude and duration of loading is influenced by an individual's intrinsic risk factors, which affect the tissue's response to loading. Intrinsic factors include the influences of nutrition, age, injury, and disease, among others [7-10]. Additionally, recent imaging studies have documented vast variations in buttocks anatomy, tissue type, and quality [11-12], which will also influence the tissue response to loading [13-14]. Magnitude and duration of loading are currently most readily measured in practice. Strategies for preventing pressure ulcers for wheelchair users therefore routinely target these factors. Pressure magnitude is managed by the selection of wheelchair cushions, other support surfaces, and body posture as one rests upon these supporting surfaces. Duration of pressure is addressed via the frequency of turning and weight-shifting activities as well as with the use of dynamic surfaces that actively redistribute pressure on the body surfaces [15].

To minimize the duration of pressure, wheelchair users who are at risk of developing sitting-acquired pressure ulcers are taught a variety of maneuvers to shift body weight off the buttocks by leaning forward and to the side or lifting their buttocks off the cushion surface. A few studies have documented that these maneuvers are effective in reducing pressures and increasing blood flow to the buttocks tissues [16-17]. Clinical guidelines recommend that persons perform pressure reliefs (PRs) with varying durations and frequencies ranging from 15 to $30 \mathrm{~s}$ every 15 to $30 \mathrm{~min}$ to $60 \mathrm{~s}$ every hour [18-21].

A few studies have investigated self-reported measures of PR behaviors but have found no significant relationship with the occurrence of pressure ulcers [22-25]. Self-reported behaviors might not have been accurate or sensitive enough to be adequately evaluated. Furthermore, protective weight-shift (WS) behaviors may include other activities in addition to dedicated PRs, and these other activities were not considered during these studies. Indeed, many functional movements, such as reaching and moving in the wheelchair seat during daily tasks, have been shown to redistribute pressure off sites at-risk for developing pressure ulcers while also increasing blood flow [17].

To further investigate the role of PRs in reducing the occurrence of pressure ulcers, we need to understand the in-seat movements of wheelchair users. Much research has been undertaken to understand how people change seated postures during occupational sitting [26-28], typically measuring movements over a short period of time.
This work has identified different types of in-seat movements, based on the magnitude, frequency, and duration of the movements. As expected, larger movements are typically done with a lower frequency than smaller movements. At this time, studies of the sitting behavior of wheelchair users have been limited to measurement of occupancy [29-33] or complete off-loadings [33-35] and a single pilot study that considered smaller movements but was never expanded to a full study [36].

Therefore, the objective of this study was to describe the in-seat movement and WS behavior of full-time wheelchair users. A secondary goal was to compare WS behavior to established PR guidelines. A fuller understanding of the behavior of wheelchair users will inform training, education, and product design to support seated movement.

\section{METHODS}

\section{Participants}

Individuals with chronic spinal cord injury (SCI) were recruited from rehabilitation facilities in the Atlanta, Georgia, and Durham, North Carolina, areas. To be considered for inclusion, potential adults needed to be at least 2 yr postinjury, use a wheelchair as their primary mobility device, and be capable of independently performing WS maneuvers.

\section{Instrumentation}

Each participant's primary wheelchair was fitted with a custom-fabricated, eight-element pressure relief monitoring (PRM) mat of force sensors. The eight piezo-resistive force sensors (Vista Medical Ltd; Winnipeg, California) were configured into two sets of four sensors and placed underneath the wheelchair cushion (Figure 1) [37]. Resistances measured by each sensor element were converted to voltages using custom-fabricated circuitry and stored as voltage on a data logger (MSR Electronics GmbH; Seuzach, Switzerland). Signals were continuously sampled at $1 \mathrm{~Hz}$ with 8-bit resolution for the duration of the instrumented period, which was typically between 1 and $2 \mathrm{wk}$. The data were retrieved at the end of this period.

\section{Protocol}

A brief training protocol (10-15 $\mathrm{min})$ was used to relate the loads and center of pressure (COP) movements 

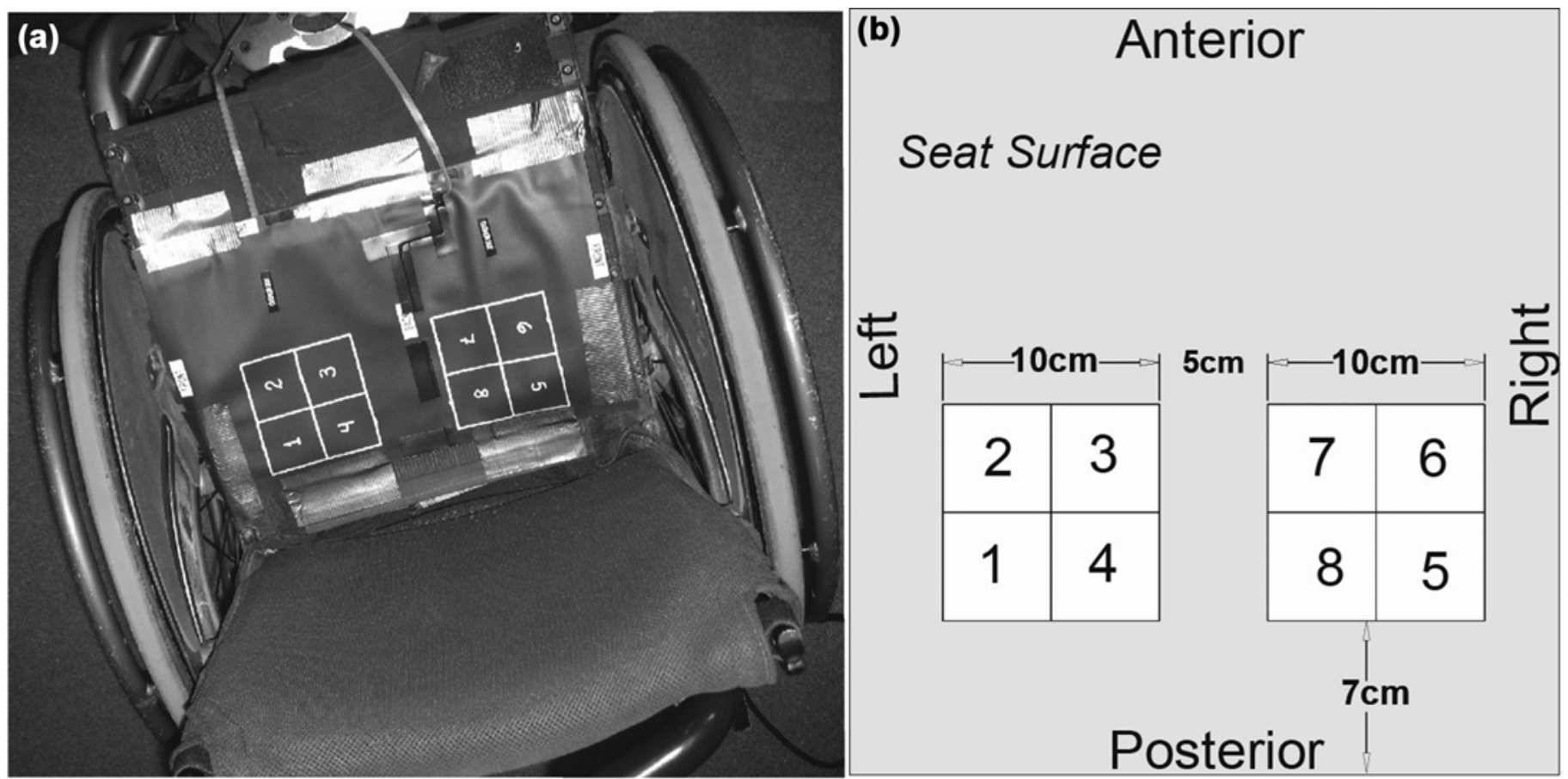

Figure 1.

Example of the pressure relief monitoring sensor mat attached to the sling seat of a manual wheelchair; (a) photograph of the wheelchair and (b) schematic of the sensor placement.

measured under the wheelchair cushion with the pressures at the buttocks/cushion interface. The training protocol was conducted at the beginning of instrumentation and repeated for some participants following the instrumentation period. Participants transferred out of their wheelchairs, the PRM mat was attached beneath their wheelchair cushion, and an FSA interface pressure mat (Vista Medical Ltd) was placed on top of their wheelchair cushion. Participants performed a prescribed series of maneuvers to mimic WSs and functional in-seat movements. These maneuvers included leans with varying degrees of trunk movement to the front, left, and right. Subjects were also asked to adopt other postures and movements that they self-identified as commonly performed and to move dynamically in their seats for one minute. Periods of stationary upright sitting and push-up PRs were interspersed among the leans. Interface pressure and PRM force data were simultaneously collected at $1 \mathrm{~Hz}$ during the training set and were later correlated to provide a ground truth for interpreting the PRM data as described subsequently.

Following the completion of the training set, the interface pressure mat was removed and participants were instructed to proceed with their normal activities as if no instrumentation was present. Standard demographics questions were asked, as well as questions about mobility and seating equipment and how individuals use their equipment. Behavioral questions included the strategies participants used to increase seated comfort, the frequency and types of PRs performed, and the purposes for which they transferred.

\section{Data Reduction}

The PRM mat data, consisting of eight independent time series of force, were initially reduced to a four-feature time series data set that was used in further processing. These features included the maximum forces measured on the left and right sides, and the location of the COP on the mat in the medial-lateral and anterior-posterior directions. The total PRM load was calculated as the sum of all eight sensor measurements and was used to determine wheelchair occupancy and complete off-loading.

Processing long-term seated force data can be challenging. The measurements during inactive sitting can change over time because of several factors, including differences in where the person sits on the cushion, drift in the sensor responses, and creep in the system. Given 
the rationale that WSs consist of transient changes in sitting posture, analysis necessitated a continually defined baseline loading condition that reflected an upright posture. Baseline series were computed for each feature by applying a zero-delay low-pass filter to the measured force time series from which the features were computed over the periods of occupancy (Figure 2). A corner frequency of $0.005 \mathrm{~Hz}(1 / 200 \mathrm{~s})$ was selected for the baseline filter from an inspection of multiple data sets. In-seat movement and WS features were then based on deviations from this baseline series.

A similar approach was used to process the interface pressure training data. First, the interface pressure data were used to calculate the peak pressure index (PPI), or the peak pressure in a 9-10 $\mathrm{cm}^{2}$ region underneath each ischial tuberosity [38], and the COP in the medial-lateral and anterior-posterior directions. In the case of the training data, the baseline was computed using the measurements during known upright sitting segments. Normalized inter- face pressure values were used as ground truth for the training protocol. Each set of PRM features was classified as a WS if the normalized interface pressure was reduced by more than 30 percent from upright sitting.

\section{Definitions of Metrics}

We chose to describe in-seat movement with a spectrum of measures that vary in magnitude and duration of unloading. The magnitude of unloading was determined by associating the PRM features with ground truth status using interface pressures from the training set measurements. These measures included wheelchair occupancy, transfers out of the chair, PR frequency, WS frequency, and in-seat activity frequency.

Wheelchair occupancy occurred when more than 10 percent of the total upright PRM force data was measured, a threshold that was validated using the interface pressure data collected during the training set. Full offloading occurred when total PRM force was reduced by



Figure 2.

Eight pressure relief monitoring sensor element forces from a single participant measured for 30 min, with baseline values indicated by dotted lines. $\mathrm{S}=$ sensor. 
90 percent or more. This full off-loading state was further categorized using its duration: Off-loading for more than 2 min was considered a transfer out of the wheelchair, and off-loading lasting between 15 and $120 \mathrm{~s}$ was defined as a $P R$.

WSs were defined as a 30 to 90 percent reduction in the interface pressure PPI values compared to upright sitting. In the training set data, all PRM features were classified as a WS or upright sitting according to the associated normalized interface pressure PPI values. PRM features from the daily data were then classified by comparing the PRM features with the training set's PRM features and associated ground truth status of upright sitting or WS. A WS was confirmed when this pressure reduction occurred on at least one ischial tuberosity and lasted at least $15 \mathrm{~s}$.

In-plane motion of the COP measured on the PRM mat was used as a proxy for subject in-seat movement [39]. The in-plane distance traversed by the COP was calculated as the square root of the sum of the squares of the finite differences of the absolute medial-lateral and anterior-posterior COP locations over a $5 \mathrm{~s}$ window. To equilibrate this distance across subjects and cushions, we calculated the relationship between the total COP distances traveled as measured on the interface pressure mat and on the PRM mat during training. The in-plane motion of the COP measured on the PRM mat throughout the data collection period was multiplied by the ratio described previously. When the distance traveled over $5 \mathrm{~s}$ was greater than $10 \mathrm{~cm}$ or the total load was reduced by 30 percent, the time point was considered active (i.e., inseat activity). This distance equates to the length of four sensor elements on the interface pressure mat used during this part of data collection. It was determined empirically with the objective to define a threshold to define active in-seat movement.

\section{Data Analysis}

The frequency of WSs, PRs, and in-seat activity were calculated for each day as the number of respective events divided by the number of hours spent in the wheelchair. Finally, an upright sitting time was defined for each day. The upright sitting time was the longest duration the individual was seated in their wheelchair without performing a PR or a WS.

Wheelchair occupancy and in-seat movement metrics were summarized over all subject days. Coefficient of variation was also computed across subject days (across- subject variation), as well as individually for each subject (within-subject variation). The individual subject coefficients of variation were then averaged to report overall within-subject variation.

\section{RESULTS}

\section{Participants}

Data was collected on 37 participants. Of these, nine participants were excluded from the present analysis due to missing data, sensor malfunctions, or failure to collect a training set. The descriptions of the remaining 28 subjects are presented in Table 1. From these 28 participants, we collected a total of 208 complete days of data with 16 of these days exhibiting less than $4 \mathrm{~h}$ spent in the wheelchair. Because those days were inconsistent with full-time use, the remaining $192 \mathrm{~d}$ were analyzed.

The 28 participants were full-time wheelchair users, predominantly with a diagnosis of SCI $(n=25)$. Injuries were mostly thoracic, with only two participants having cervical injuries. Level of function among participants was similar because all participants used a wheelchair full time and were independent in wheelchair use and transfer (only one participant required a lift or hoist for his transfers). Eleven of the participants had a history of multiple pelvic pressure ulcers.

Table 1.

Characteristics of study participants $(N=28)$.

\begin{tabular}{lc}
\hline \multicolumn{1}{c}{ Characteristic } & $\boldsymbol{n}(\%)$ or \\
Sex & $22(79)$ \\
Male & $6(21)$ \\
Female & \\
Race & $11(39)$ \\
Black/African American & $15(54)$ \\
White & $2(7)$ \\
Other/Not Reported & \\
Occupation & $13(46)$ \\
Employed & $11(39)$ \\
Unemployed & $3(11)$ \\
Student & $1(3)$ \\
Not Reported & $41 \pm 12(21-66)$ \\
Age, yr $(n=27)$ & $70 \pm 4(60-77)$ \\
Height, in. $(n=27)$ & $175 \pm 43(93-180)$ \\
Weight, lb $(n=26)$ & $14 \pm 10(2-33)$ \\
Time in Wheelchair, yr & \\
\hline SD = standard deviation. &
\end{tabular}


All participants used ultra-light manual wheelchairs. They sat on a variety of wheelchair cushions, with Roho (ROHO Inc; Belleville, Illinois) products being the most common $(n=11)$, along with Jay (Sunrise Medical; Fresno, California) $(n=5)$, Varilite (Cascade Designs, Inc; Seattle, Washington) $(n=4)$, Ride (Ride Designs; Littleton, Colorado) $(n=3)$, Matrx (Invacare Corporation; Elyria, Ohio) $(n=2)$, and other products $(n=2)$. Wheelchair cushions varied in age, with a mean \pm standard deviation of $2.3 \pm 2.0 \mathrm{yr}$ and range of $1 \mathrm{wk}$ to $7 \mathrm{yr}$ old.

\section{Behavioral Self-Report}

When asked what strategies were used to increase seated comfort, participants reported transferring to other surfaces and/or readjusting their posture within the wheelchair seat. In response to questions about WS and transfer behaviors, 86 percent of participants reported doing complete (depression or push-up) lifts for PR, and 35 to 45 percent reported performing front leans, partial leans, and side leans.

The majority of participants in this study transferred out of their wheelchair to perform bowel/bladder routines ( $n=25)$, shower $(n=27)$, travel in a vehicle $(n=26)$, or sit in a different chair such as a couch or recliner $(n=21)$. Only six participants reported transferring to sit in a different wheelchair.

\section{Wheelchair Occupancy and In-Seat Movement}

Over $192 \mathrm{~d}$ in which participants spent at least $4 \mathrm{~h}$ in their wheelchairs, participants spent an average of $10.6 \mathrm{~h}$ per day in their wheelchairs, which is consistent with the inclusion criteria of full-time wheelchair use (Table 2). PR frequency ranged from 0 to 2.8 times per hour, and WS frequency ranged from 0 to 15.4 times per hour, though both frequencies were skewed toward 0 with median frequencies of 0.2 and 1.8, respectively (Table 2, Figure 3). In order to compare the WS and PR frequencies to the clinical guidelines, which recommend PRs every 15 to $60 \mathrm{~min}$, the 95 percent confidence intervals of the average time between WSs and PRs were computed. The intervals suggest that PRs were not done at a frequency meeting clinical guidelines, with a 95 percent confidence interval of 214 to 296 min between PRs on days when at least one PR was done. However, WSs did meet the recommendation of performing one every $60 \mathrm{~min}$ with a 95 percent confidence interval of 49 to $75 \mathrm{~min}$ between WSs.

In addition to the typical or average frequency of WSs, it is important to consider the range and distribution of behaviors within a day. For example, even though WS frequency exceeded 2 per hour, it does not guarantee 2 WSs every hour. Therefore, the longest period of time a participant spent seated between unloading events (upright sitting) was calculated for each day. On the average day, subjects had an upright sitting segment lasting $140 \mathrm{~min} \pm 84$ min without performing a WS or PR (Figure 4).

Variations from day to day for a single participant were highest for the frequencies of PRs and WSs, though the day-to-day variations of other variables were still quite high (Table 2). Variability between participants was even higher, with PR and WS frequencies also being the highest.

With such high variability across and within subjects, it is difficult to present a "typical” participant. Therefore, examples of $9 \mathrm{~h}$ of in-seat movement from three very different participants are displayed in Figure 5. The figure plots in-seat activity over time. High amplitudes and spikes of this value illustrate brief movements by the

Table 2.

Daily wheelchair occupancy and in-seat movement across $192 \mathrm{~d}$.






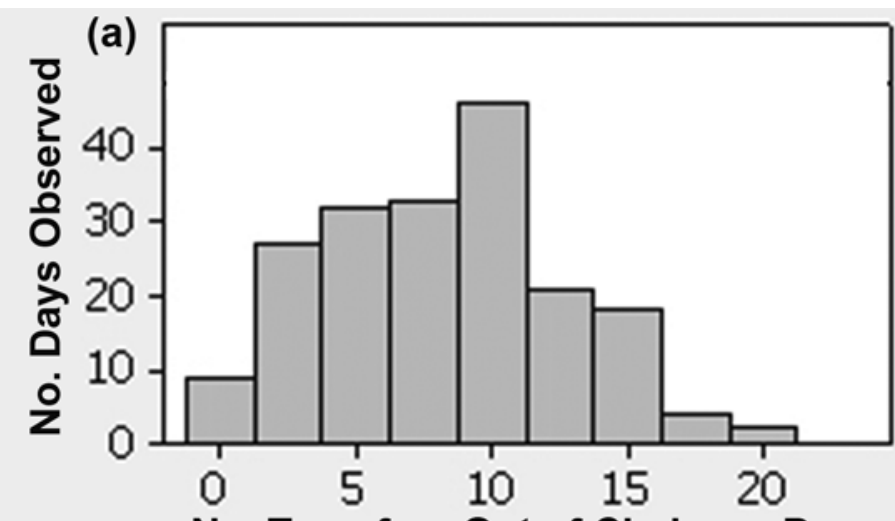

No. Transfers Out of Chair per Day

(c)

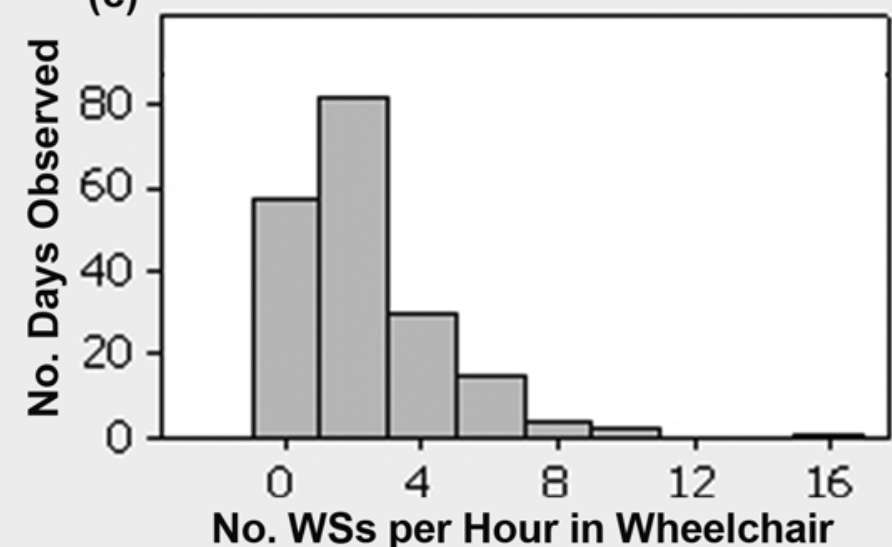

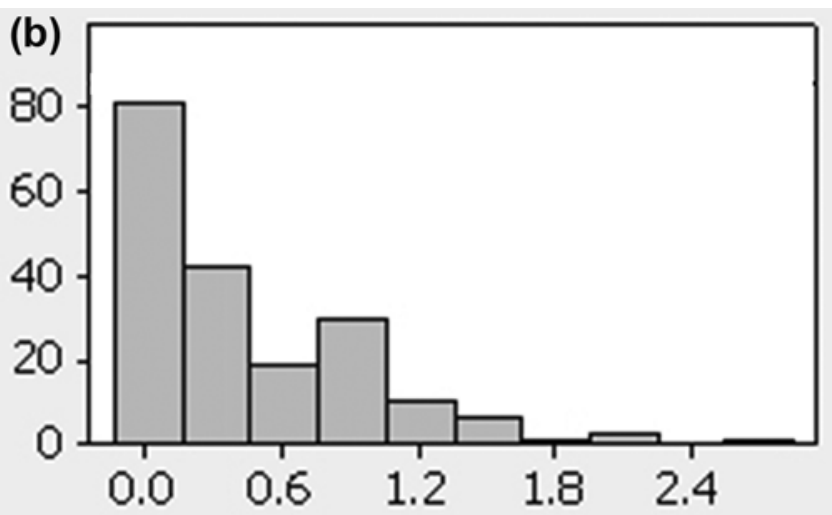

No. PRs per Hour in Wheelchair



No. In-Seat Activities per Hour in Wheelchair

Figure 3.

Histograms of daily metrics of in-seat movement: (a) number (No.) of transfers out of chair, (b) frequency of pressure reliefs (PRs) per hour, (c) frequency of weight shifts (WSs) per hour, and (d) frequency of in-seat activity. These histograms illustrate the skewed distributions of WS and PR frequencies. Transfer count and in-seat activity were more normally distributed.

participant that are not defined as WSs because the posture was not held for the minimum duration of $15 \mathrm{~s}$. Sections where the in-seat activity equals zero reflect the times that individuals were not seated in their wheelchairs. Subject A transferred frequently throughout the day, while Subject B remained seated for the majority of the day. Subject A did not move much while in the wheelchair and performed few WSs throughout the day. Despite remaining in the chair for the entire day, Subject $\mathrm{B}$ was rarely stationary, regularly moving his COP. Yet he rarely maintained the postural shifts long enough for them to be defined as a WS. Subject C performed an above average number of PRs and had high in-seat movement as reflected by activity frequency.

\section{DISCUSSION}

This study was the first to monitor and investigate inseat movement of wheelchair users during their everyday lives. Measurements of wheelchair occupancy and transfers were consistent with prior work investigating wheelchair use for individuals who use a manual wheelchair [31-33]. The low frequency of complete off-loading, or PRs, has been indicated in previous studies [33,35]. Selfreported PR behaviors in the literature were less consistent with behavior measured in this study. In a survey of individuals with SCI, nearly 50 percent of participants reported doing "some type of pressure relief" every $30 \mathrm{~min}$ “often” or "always” [22]. Yet approximately 30 percent of days studied here had fewer than one WS per hour, and 


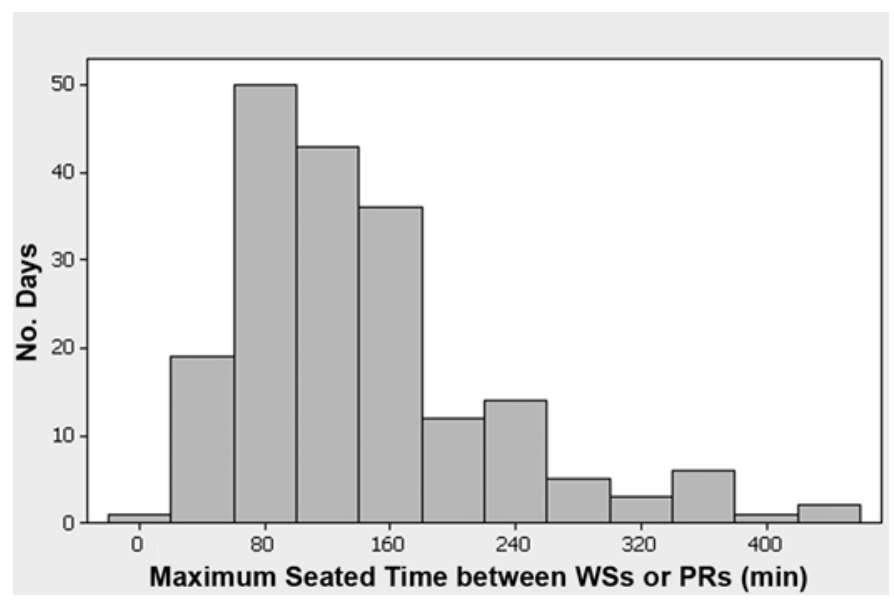

Figure 4.

Histogram of the longest upright sitting segments between weight shifts (WSs) or pressure reliefs (PRs) on each of the $192 \mathrm{~d}$ studied. No. $=$ number.

more than 90 percent of days studied had at least a single $1 \mathrm{~h}$ segment with no WSs. With no literature available about objectively measured in-seat movement in everyday life for this population, the only comparisons available are short time-frame studies of seated movement in nondisabled adults. For example, during 90 min of computer work, adults shifted (defined by a $5^{\circ}$ trunk movement lasting at least $15 \mathrm{~s}$ ) 4.7 times per hour, nearly twice as often as WSs were performed by the current population [27]. However, the definition of a shift in the study by Dunk and Callaghan was more sensitive and included smaller movements than our definition of a WS. Other studies reported on transient movements that did not require a minimum duration. Results of these studies varied widely from 8 to 72 movements per hour [26,28,4041]. The present study found that in-seat activity occurred at a frequency of 42 times per hour, placing it on the same order of magnitude as published results using nondisabled participants.

\section{WS Frequency}

One important finding from this study was that WSs were performed much more frequently than PRs, with no participants meeting the clinical guidelines of two PRs per hour on a daily basis. Despite the limited PRs, WSs were performed closer to twice per hour for many subject days. This behavioral characteristic is very consistent with the reported activities of participants using their powered wheelchairs' tilt-in-space feature, whereby small tilts were performed two to three times per hour, but large tilts were rarely performed [30,32]. In previous work, we demonstrated that intermediate leans, which reduced pressure between 29 and 46 percent, resulted in increased blood flow on the order of 100 to 300 percent [17]. This result highlights the potential benefits of functional leans referred to as WSs in this study. Therefore, while training and encouraging PRs, clinicians are advised to include WS techniques as part of their wheelchair seating evaluations and training to support tissue health. Using interface pressure mapping as a feedback tool when training patients to do WS and PR behaviors can be very helpful [42].

In between WSs, participants rarely adopted a completely static posture. In-seat activity, as measured by the movement of the COP and reductions in total load, occurred frequently. Similar small movements of short duration were seen in a 2002 pilot study [36]. Although the effects of these movements on blood flow may be less significant [17,43-44], they have the potential to change the internal deformation of tissue [11,45] and may provide important physiological benefits in terms of pressure ulcer prevention. Furthermore, small movements have the potential to help dissipate heat and reduce humidity [46]. Future work to determine the role of in-seat movement in preventing pressure ulcers needs to focus on WSs and in-seat activity in addition to PRs because PRs do not fully reflect the changes in buttocks loading that occur throughout the day.

\section{Lack of Daily Routines}

Neither WSs nor PRs were performed in a routine manner. Day-to-day variations were 44 and 58 percent respectively (Table 2), and as illustrated in Figure 5, WSs were not evenly distributed throughout the day. In fact, even as participants performed approximately two WSs per hour on average, half of the subject days included a $2 \mathrm{~h}$ stretch in which no WSs were performed (Figure 4). Therefore, clinicians should not assume that individuals will adopt a WS routine. Consequently, seating evaluations should emphasize positioning individuals in a manner that allows for postural changes while seated. Facilitating reaching and leaning in a safe manner not only promotes function but can have an effect on buttocks loading. Additionally, the finding that, on occasion, a longer duration of loading can be safely maintained without pressure ulcer development should be noted. This 
(a)

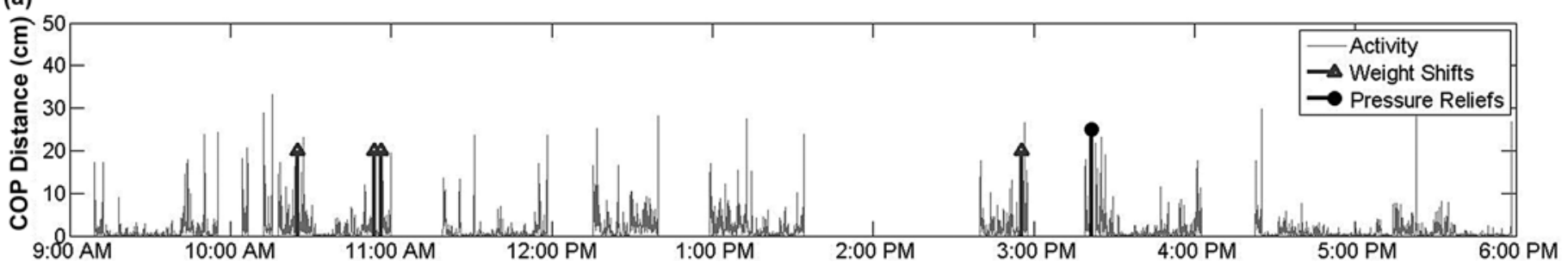

(b)

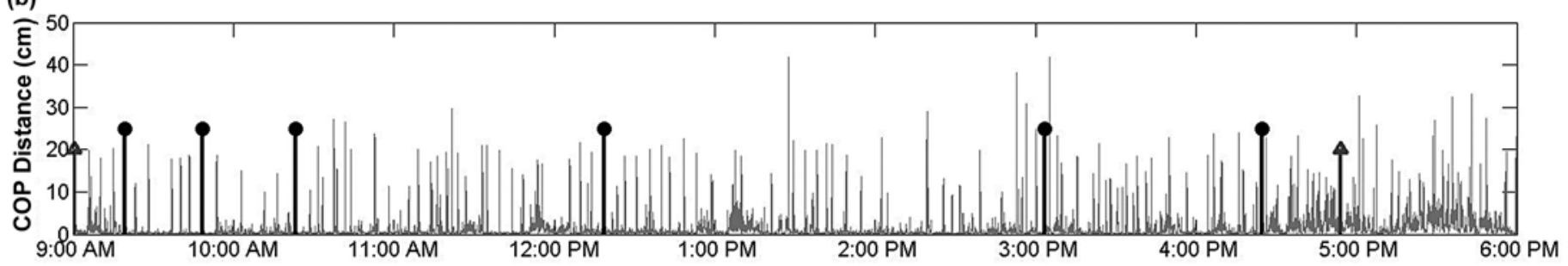

(c)



Figure 5.

In-seat movements for (a) Subject A, (b) Subject B, and (c) Subject C. The light gray trace represents in-seat activity during a 5 s window, and the dark gray triangular and black circular stems represent weight shifts and pressure reliefs, respectively. COP = center of pressure.

result should also motivate further work understanding the physiological benefits of smaller in-seat movements.

\section{Frequent Transfers}

Despite spending more than $10 \mathrm{~h}$ per day in their wheelchairs, individuals in this cohort performed many transfers out of the wheelchair. Half of the monitored days included more than 8 transfers out of the wheelchair or more than 16 transfers (including transfers returning to the wheelchair). Many of our participants reported transferring for toileting, showering, and changing sitting surfaces. The clinical implications of this observation are many. First, transfer technique is incredibly important given the number of transfers performed during the day. Proper transfer technique may reduce falls and limit upper limb discomfort and damage secondary to the high number of daily transfers [47]. Second, a seating system and an environment that are conducive to safe, efficient transfers are also important for improving safety and function. Because wheelchair users transfer out of their wheelchair often, clinicians must also counsel users to assess where they sit when out of the chair, including reflection on the surface and their posture. Finally, the frequent transfers make it more difficult to assign the cause of pressure ulcer to the wheelchair cushion. Inquiring about where else the individual sits (aside from the wheelchair) is important during an evaluation.

\section{Limitations}

This observational study provides a thorough overview of in-seat movement. The population of full-time wheelchairs users studied was mostly diagnosed with SCI, so it is unclear whether behavior would differ in other populations. Also this study only includes individuals who have used a wheelchair for more than $2 \mathrm{yr}$. Future work should assess WS behavior during the first 
years following injury, when behavioral patterns are first established.

The manner in which the PRM data were collected, by measuring forces underneath the wheelchair cushion, also presents a limitation. We used this method because placing an interface pressure mat at the buttocks/cushion interface presents practical challenges, including interfering with the performance of the wheelchair cushion [48]. The forces measured underneath the wheelchair cushion are related to the forces transferred from the user to the cushion. Therefore, changes in the users' posture alter the force distribution underneath the cushion. Because these relationships were determined for each individual, we believe PRM force data are a valid measure of seated posture, and, by extension, changes in posture. That being said, we cannot measure the intent of a person's movement, so we defined WSs and PRs based on mathematical algorithms.

Finally, because subjects knew that their WSs and PRs were being monitored, it is possible that they could have altered their sitting behaviors. Because the findings illustrate that WS and PR behaviors fall well below the regimens that are taught to wheelchair users, this potential effect does not change the overall findings. Moreover, the within-subject variability in WS and PR behavior did not indicate that participants adopted a behavioral routine that one would expect if they were consciously reacting to being monitored.

\section{CONCLUSIONS}

This study represents the first objective description of everyday sitting behavior of individuals who use a wheelchair full time. Measurements of seated behavior suggested that individuals who use a wheelchair full time typically did not perform frequent PRs. They did perform more frequent WSs, often consistent with clinical guidelines, but without any routine to the timing. They also transferred to other surfaces frequently throughout the day. Given these observations, seating evaluations should emphasize positioning individuals in a manner that facilitates reaching, leaning, and transferring in a safe manner. Clinicians should also consider educating patients about WS techniques in addition to PR techniques and should consider using interface pressure as a feedback tool in the process. Additional emphasis should be placed on teach- ing transfer techniques and counseling users regarding the other surfaces on which they sit.

\section{ACKNOWLEDGMENTS}

\section{Author Contributions:}

Study design and data collection: S. E. Sonenblum, S. H. Sprigle. Data analysis and interpretation and manuscript preparation, revision, final review, and approval: S. E. Sonenblum, S. H. Sprigle, J. S. Martin. Financial Disclosures: The authors have declared that no competing interests exist.

Funding/Support: This material was based on work supported by the Mobility Rehabilitation Engineering Research Center, which is funded by the National Institute on Disability, Independent Living, and Rehabilitation Research (grant H133E080003). Support for this study was also provided through the U.S. Department of Defense (grant W81XWH-13-1-0387).

Additional Contributions: The authors acknowledge Kevin Caves and Helen Hoenig at Duke University and the Durham Department of Veterans Affairs Medical Center, and Chris Maurer, David Kreutz, and Jennith Bernstein at Shepherd Center for their efforts with participant recruitment and data collection. We also acknowledge Ricardo Lopez, MS, for his work developing the data collection hardware; Dr. Rui Dai for her work on the data analysis method; and Teddy Lisette Vonk, MS, who assisted with participant recruitment and data collection. Institutional Review: Approval was obtained from local institutional review boards at rehabilitation facilities in the Atlanta, Georgia, and Durham, North Carolina, areas, and informed consent was obtained from all participants prior to their participation in the study.

Participant Follow-Up: The authors have no plans to notify the study subjects of the publication of this article because the research protocol has been closed and all communications ceased at that time.

\section{REFERENCES}

1. Kosiak M. Etiology and pathology of ischemic ulcers. Arch Phys Med Rehabil. 1959;40(2):62-69. [PMID:13618101]

2. Reswick JB, Rogers JE. Experience at Rancho Los Amigos Hospital with devices and techniques to prevent pressure sores. In: Kenedi R, Cowden J, Scales J, eds. Bed sore biomechanics. London: Macmillan; 1976. p. 301-10.

3. Oomens CW, Bressers OF, Bosboom EM, Bouten CV, Blader DL. Can loaded interface characteristics influence strain distributions in muscle adjacent to bony prominences? Comput Methods Biomech Biomed Engin. 2003; 6(3):17180. [PMID:12888429]

http://dx.doi.org/10.1080/1025584031000121034

4. Gawlitta D, Li W, Oomens CW, Baaijens FP, Bader DL, Bouten CV. The relative contributions of compression and hypoxia to development of muscle tissue damage: An in vitro study. Ann Biomed Eng. 2007;35(2):273-84. 


\section{[PMID:17136445]}

http://dx.doi.org/10.1007/s10439-006-9222-5

5. Loerakker S, Manders E, Strijkers GJ, Nicolay K, Baaijens FP, Bader DL, Oomens CW. The effects of deformation, ischemia, and reperfusion on the development of muscle damage during prolonged loading. J Appl Physiol. 2011; 111(4):1168-77.

6. Bouten CV, Oomens CW, Baaijens FP, Bader DL. The etiology of pressure ulcers: Skin deep or muscle bound? Arch Phys Med Rehabil. 2003;84(4):616-19. [PMID:12690603] http://dx.doi.org/10.1053/apmr.2003.50038

7. Bergstrom N, Braden BJ, Laguzza A, Holman V. The Braden Scale for Predicting Pressure Sore Risk. Nurs Res. 1987;36(4):205-10. [PMID:3299278]

http://dx.doi.org/10.1097/00006199-198707000-00002

8. Salzberg CA, Byrne DW, Cayten CG, van Niewerburgh P, Murphy JG, Viehbeck M. A new pressure ulcer risk assessment scale for individuals with spinal cord injury. Am J Phys Med Rehabil. 1996;75(2):96-104. [PMID:8630201] http://dx.doi.org/10.1097/00002060-199603000-00004

9. Marin J, Nixon J, Gorecki C. A systematic review of risk factors for the development and recurrence of pressure ulcers in people with spinal cord injuries. Spinal Cord. 2013;51(7):522-27. [PMID:23588570]

http://dx.doi.org/10.1038/sc.2013.29

10. Mortenson WB, Miller WC, SCIRE Research Team. A review of scales for assessing the risk of developing a pressure ulcer in individuals with SCI. Spinal Cord. 2008; 46(3):168-75. [PMID:17909557]

http://dx.doi.org/10.1038/sj.sc.3102129

11. Sonenblum SE, Sprigle SH, Cathcart JM, Winder RJ. 3D anatomy and deformation of the seated buttocks. J Tissue Viability. 2015;24(2):51-61. [PMID:25935874] http://dx.doi.org/10.1016/j.jtv.2015.03.003

12. Wu GA, Bogie KM. Not just quantity: Gluteus maximus muscle characteristics in able-bodied and SCI individuals-Implications for tissue viability. J Tissue Viability. 2013;22(3):74-82. [PMID:23615320] http://dx.doi.org/10.1016/j.jtv.2013.03.003

13. Loerakker S, Solis LR, Bader DL, Baaijens FP, Mushahwar VK, Oomens CW. How does muscle stiffness affect the internal deformations within the soft tissue layers of the buttocks under constant loading? Comput Methods Biomech Biomed Engin. 2013;16(5):520-29. http://dx.doi.org/10.1080/10255842.2011627682

14. Sopher R, Nixon J, Gorecki C, Gefen A. Effects of intramuscular fat infiltration, scarring, and spasticity on the risk for sitting-acquired deep tissue injury in spinal cord injury patients. J Biomech Eng. 2011;133(2):021011.

[PMID:21280883]

http://dx.doi.org/10.1115/1.4003325
15. Sprigle S, Sonenblum S. Assessing evidence supporting redistribution of pressure for pressure ulcer prevention: A review. J Rehabil Res Dev. 2011;48(3):203-13.

[PMID:21480095]

http://dx.doi.org/10.1682/JRRD.2010.05.0102

16. Coggrave MJ, Rose LS. A specialist seating assessment clinic: Changing pressure relief practice. Spinal Cord. 2003;41(12):692-95. [PMID:14639449] http://dx.doi.org/10.1038/sj.sc.3101527

17. Sonenblum SE, Vonk TE, Janssen TW, Sprigle SH. Effects of wheelchair cushions and pressure relief maneuvers on ischial interface pressure and blood flow in people with spinal cord injury. Arch Phys Med Rehabil. 2014;95(7): 1350-57. [PMID:24480336] http://dx.doi.org/10.1016/j.apmr.2014.01.007

18. Institute for Clinical Systems Improvement. Pressure ulcer prevention and treatment protocol. Health care protocol. Bloomington (MN): Institute for Clinical Systems Improvement; 2012. 88 p.

19. National Pressure Ulcer Advisory Panel, European Pressure Ulcer Advisory Panel, and Pan Pacific Pressure Injury Alliance. Prevention and treatment of pressure ulcers: Quick reference guide. Haesler E, ed. Perth (Australia): Cambridge Media; 2014.

20. Nawoczenski DA. Pressure sores: Prevention and management. In: Buchanan LE, Nawoczenski DA, eds. Spinal cord injury: Concepts and management approaches. Baltimore (MD): Williams \& Wilkins; 1987.

21. Sliwinski MM, Druin E. Intervention principles and position change. In: Sisto SA, Druin E, Sliwinski MM, eds. Spinal cord injuries: Management and rehabilitation. St. Louis (MO): Mosby Elsevier; 2009.

22. Bloemen-Vrencken JH, de Witte LP, Post MW, van den Heuvel WJ. Health behaviour of persons with spinal cord injury. Spinal Cord. 2007;45(3):243-49. [PMID:16969357] http://dx.doi.org/10.1038/sj.sc.3101967

23. Garber SL, Rintala DH, Hart KA, Fuhrer MJ. Pressure ulcer risk in spinal cord injury: Predictors of ulcer status over 3 years. Arch Phys Med Rehabil. 2000;81(4):465-71. [PMID:10768537] http://dx.doi.org/10.1053/mr.2000.3889

24. Krause JS, Broderick L. Patterns of recurrent pressure ulcers after spinal cord injury: Identification of risk and protective factors 5 or more years after onset. Arch Phys Med Rehabil. 2004;85(8):1257-64. [PMID:15295750] http://dx.doi.org/10.1016/j.apmr.2003.08.108

25. Raghavan P, Raza WA, Ahmed YS, Chamberlain MA. Prevalence of pressure sores in a community sample of spinal injury patients. Clin Rehabil. 2003;17(8):879-84. [PMID:14682560] http://dx.doi.org/10.1191/0269215503cr692oa 
26. Bhatnager V, Drury CG, Schiro SG. Posture, postural discomfort, and performance. Hum Factors. 1985;27(2):18999. [PMID:4018811]

27. Dunk NM, Callaghan JP. Lumbar spine movement patterns during prolonged sitting differentiate low back pain developers from matched asymptomatic controls. Work. 2010;35(1):3-14. [PMID:20164621]

28. Na S, Sunghyun L, Hwa-Soon C, Chunga MK. Evaluation of driver's discomfort and postural change using dynamic body pressure distribution. Int J Ind Ergon. 2005;35(12): 1085-96. http://dx.doi.org/10.1016/j.ergon.2005.03.004

29. Ding D, Leister E, Cooper RA, Cooper R, Kelleher A, Fitzgerald SG, Boninger ML. Usage of tilt-in-space, recline, and elevation seating functions in natural environment of wheelchair users. J Rehabil Res Dev. 2008;45(7): 973-83. [PMID:19165687] http://dx.doi.org/10.1682/JRRD.2007.11.0178

30. Sonenblum SE, Sprigle S. Distinct tilting behaviours with power tilt-in-space systems. Disabil Rehabil Assist Technol. 2011;6(6):526-35. [PMID:21561230] http://dx.doi.org/10.3109/17483107.2011.580900

31. Sonenblum SE, Sprigle S, Lopez RA. Manual wheelchair use: Bouts of mobility in everyday life. Rehabil Res Pract. 2012;2012:1-7. [PMID:22848837] http://dx.doi.org/10.1155/2012/753165

32. Sonenblum SE, Sprigle S, Maurer CL. Use of power tilt systems in everyday life. Disabil Rehabil Assist Technol. 2009;4(1):24-30. [PMID:19172478] http://dx.doi.org/10.1080/17483100802542744

33. Yang YS, Chang GL, Hsu MJ, Chang JJ. Remote monitoring of sitting behaviors for community-dwelling manual wheelchair users with spinal cord injury. Spinal Cord. 2009;47(1):67-71. [PMID:18560373] http://dx.doi.org/10.1038/sc.2008.72

34. Merbitz CT, King RB, Bleiberg J, Grip JC. Wheelchair push-ups: Measuring pressure relief frequency. Arch Phys Med Rehabil. 1985;66(7):433-38. [PMID:4015355]

35. Chawla JC, Andrews B, Bar C. Using warning devices to improve pressure-relief training. Paraplegia. 1979;16(4): 413-19. [PMID:431972] http://dx.doi.org/10.1038/sc.1978.75

36. Bain DS, Ferguson-Pell M. Remote monitoring of sitting behavior of people with spinal cord injury. J Rehabil Res Dev. 2002;39(4):513-20. [PMID:17638148]

37. Dai R, Sonenblum SE, Sprigle S. A robust wheelchair pressure relief monitoring system. Conf Proc IEEE Eng Med Biol Soc. 2012;2012:6107-6110. [PMID:23367322]

38. Sprigle S, Dunlop W, Press L. Reliability of bench tests of interface pressure. Assist Technol. 2003;15(1):49-57. [PMID:14760981] http://dx.doi.org/10.1080/10400435.2003.10131889
39. Fenety PA, Putnam C, Walker JM. In-chair movement: Validity, reliability and implications for measuring sitting discomfort. Appl Ergon. 2000;31(4):383-93.

[PMID:10975665]

http://dx.doi.org/10.1016/S0003-6870(00)00003-X

40. Linder-Ganz E, Scheinowitz M, Yizhar Z, Margulies SS, Gefen A. How do normals move during prolonged wheelchair-sitting? Technol Health Care. 2007;15(3):195-202. [PMID:17473399]

41. Reenalda J, Van Geffen P, Nederhand M, Jannink M, IJzerman M, Rietman H. Analysis of healthy sitting behavior: Interface pressure distribution and subcutaneous tissue oxygenation. J Rehabil Res Dev. 2009;46(5):577-86. [PMID:19882492] http://dx.doi.org/10.1682/JRRD.2008.12.0164

42. Sprigle S, Sonenblum S, Conner-Kerr T. MobilityRERC State of the Science Conference: Individualizing pressure ulcer risk and prevention strategies. Disabil Rehabil Assist Technol. 2013;8(6):454-61. [PMID:24206367] http://dx.doi.org/10.3109/17483107.2013.823574

43. Sonenblum SE, Sprigle SH. The impact of tilting on blood flow and localized tissue loading. J Tissue Viability. 2011;20(1):3-13. [PMID:21145240] http://dx.doi.org/10.1016/j.jtv.2010.10.001

44. Jan YK, Jones MA, Rabadi MH, Foreman RD, Thiessen A. Effect of wheelchair tilt-in-space and recline angles on skin perfusion over the ischial tuberosity in people with spinal cord injury. Arch Phys Med Rehabil. 2010;91(11):175864. [PMID:21044723] http://dx.doi.org/10.1016/j.apmr.2010.07.227

45. Shabshin N, Ougortsin V, Zoizner G, Gefen A. Evaluation of the effect of trunk tilt on compressive soft tissue deformations under the ischial tuberosities using weight-bearing MRI. Clin Biomech (Bristol, Avon). 2010;25(5):402-8. [PMID:20188448] http://dx.doi.org/10.1016/j.clinbiomech.2010.01.019

46. Sprigle S, Eicholtz M. Temperature and humidity at the buttock-wheelchair cushion interface. In: Annual Fall Scientific Meeting of the Biomechanical Engineering Society (BMES); 2009 Oct 7-10; Pittsburgh, PA.

47. Tsai CY, Hogaboom NS, Boninger ML, Koontz AM. The relationship between independent transfer skills and upper limb kinetics in wheelchair users. Biomed Res Int. 2014;2014:1-12. [PMID:25162039] http://dx.doi.org/10.1155/2014/984526

48. Pipkin L, Sprigle S. Effect of model design, cushion construction, and interface pressure mats on interface pressure and immersion. J Rehabil Res Dev. 2008;45(6):875-82.

[PMID:19009473]

http://dx.doi.org/10.1682/JRRD.2007.06.0089 
Submitted for publication July 10, 2015. Accepted in revised form October 2, 2015.

This article and any supplemental material should be cited as follows:

Sonenblum SE, Sprigle SH, Martin JS. Everyday sitting behavior of full-time wheelchair users. J Rehabil Res
Dev. 2016;53(5):585-98.

http://dx.doi.org/10.1682/JRRD.2015.07.0130

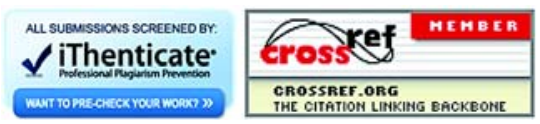


